\title{
Blended Learning Experience of Students Participating Pedagogical Formation Program: Advantages and Limitation of Blended Education
}

\author{
Fatih Saltan ${ }^{1}$ \\ ${ }^{1}$ Department of Computer Education \& Instructional Technology, Amasya University, Akbilek Mah. Muhsin \\ Yazıcıoğlu Cad. No:7, 05100, Amasya, Turkey \\ Correspondence: Fatih Saltan, Department of Computer Education \& Instructional Technology, Amasya University, \\ Akbilek Mah. Muhsin Yazıcıoğlu Cad. No:7, 05100, Amasya, Turkey
}

Received: October 17, 2016

Accepted: November 9, 2016

Online Published: November 15, 2016

doi:10.5430/ijhe.v6n1p63

URL: http://dx.doi.org/10.5430/ijhe.v6n1p63

\begin{abstract}
The aim of this study was to investigate the learning experience of students studying pedagogic formation in blended design with regard to attendance, self confidence, and attitudes toward both Pedagogic Formation Program (PFP) and the teaching profession. In order to achieve this aim, a qualitative case study approach was carried out. The participants of this study consisted of 154 graduated Faculty of Arts and Sciences students who were enrolled in the first blended PFP in Turkey. A qualitative case study was conducted. Data were obtained through an open-ended questionnaire $(n=154)$ and focus group interviews $(n=8)$. The qualitative data were analyzed by using content analysis techniques. Overall, the results indicated that blended PFP was highly promising regarding professional development, self-confidence, accessibility and eliminating some disadvantages of distance education. Specifically, inherent problems of online education continued to take place in blended design but a balanced blended approach could minimize these weaknesses. Participants indicated that face-to-face sections were more applied, authentic and effective than the online part. On the other hand, most of the participants preferred to attend the online lessons regularly. It was mainly because of availability concerns, travelling, and comfort of their home.
\end{abstract}

Keywords: Pedagogical issues, Blended education, Distance education, Teaching/learning strategies, Lifelong learning

\section{Introduction}

The majority of teacher candidates today have grown up with digital technologies like the Internet, smart phones and tablets. Teacher educators are under pressure to review and revise their programs to provide more effective and cost efficient ways of instruction. It is critical to employ instructional time in the most appropriate ways possible. In the past two decades, a large number of online-only and blended courses have been developed by higher education programs to respond to "diverse needs and desires of students and the need for more time to cover increasing curricular demands" (Garrison \& Kamuka, 2004). Almost all universities have recognize the potential of online courses and they have become an essential strategy in their overall programs (Collopy \& Arnold, 2009; Martyn, 2003; Carlson, 2004; Pethokoukis, 2002). Even universities that do not offer such courses have been using learning management systems in various scopes. Many institutions have noted that "integrating technology into instruction certainly improves access to information" (Delialioglu \& Yildirim, 2008). On the other hand, online courses have not only become a destination for many of them, but also the beginning of a new paradigm and a new pedagogical method called a blended or hybrid approach. Blended learning is defined as "the thoughtful integration of classroom face-to-face learning experiences with online learning experiences" (Garrison \& Kanuka, 2004, p. 96). This mixed delivery method has been named "the best characteristics of online education" (Martyn, 2003, p.18). The main point in blended approach is to cover the various learning needs of the students who have diverse learning styles and preferences. The blended approach also offers the opportunity to use time in a more effective and flexible way by extending instruction time out of the class walls. Educators have been excited by the potential of the blended design that provides new possibilities to face-to-face education including spending less money on travel, extending course availabilities, diversifying learning benefits and eliminating some social and psychological barriers (Beard \& Harper, 2002; Guidera, 2004). In several studies, it was emphasized that the blended approach had a positive effect on students' learning (Chak \& Fung, 2015; Zurita, Hasbun, Baloian, \& Jerez, 2015; Tuckman, 2002; Lilja, 2001). Garrison and Kamuka (2004, p. 99) asserted, "blended learning offers possibilities to create transformative 
environments that can effectively facilitate learning. It also represents a new challenge for higher education instructors to provide the necessary teaching presence in a blended environment." On the other hand, in the last decade several experimental studies have been conducted to compare traditional courses with blended courses. For example, in their experimental study, Delialioglu and Yildirim (2008) find that there was no significant mean difference between the blended and traditional courses. Despite this, they highlight that the blended approach is promising because it reduces students' classroom seat time about 66 percent and secondarily affects teaching costs. This result recalls the previous comparisons of online learning with face-to-face learning. Especially in course performance, a significant difference between online and face-to-face environments was not found (Aragon, Johnson, \& Shaik, 2002). Similarly, Collopy and Arnold (2009) indicated that graduate students could utilize and apply content understanding in either environment. In their SWOT analysis study, Jackson and Helms (2008) pointed to strengths and weaknesses of the blended courses. Research showed that students asserted equal number of strengths and weaknesses of blended approach. This result is very similar to the earlier comparison studies of distance education (e.g., Klesius, Homan, \& Thompson, 1997). In other words, the blended approach was perceived as having the same weaknesses as the online or distance education. Aragon, Johnson and Shaik (2002) compared the relationship between learning style preferences and learner success of students in an online course with an equivalent face-to-face course and found that motivation was the only variable that influenced course performance. Additionally, blended design that provides online learning opportunities reach students who otherwise would not participate in exclusively face-to-face classes. Surely, educators have to find a balance between time spent face-to-face and time spent online that reflects the various needs of the students, their learning styles, and communication styles (Collopy \& Arnold, 2009; Ko \& Rossen, 2008). Otherwise, a poorly balanced blended learning environment may not be sufficient as well as only online or tradition design. To degree to which the whole program and single courses should being online has gained importance.

Even though, as stated by Russell (1999) and some other researchers, technology does not improve learning, many strategists emphasize that "the main reason to pursue quality is to satisfy customers" (Jackson \& Helms, 2008, p.8). In this regard, the satisfaction of students who are attending blended courses has gained more importance. Many studies point out that students prefers blended courses (Delialioglu \& Yildirim, 2008). In the literature, many studies generally indicate advantages of the blended design. Many studies only focus on graduate students and nontraditional programs (Collopy \& Arnold, 2009). However, there are a limited number of studies that explore the experience of participants in specific conditions like teacher education. This study attempts to address this important need in the literature by investigating the pedagogic formation students experience in a blended program.

Specifically, this study addresses teacher candidates' attendance, self confidence, and attitudes toward both PFP and the teaching profession in blended design.

\subsection{The Purpose of the Study}

The purpose of the current study was to investigate the learning experience of students studying pedagogic formation in blended design with regard to attendance, self confidence, and attitudes toward both PFP and the teaching profession. In scope of this purpose, following specific research questions were addressed;

1. Which factors shape students' attendance in both face-to-face education and in online education in a blended environment?

2. What are the views of students regarding the effectiveness of face-to-face and online education on their professional development?

3. How do students perceive online education in blended PFP? What are the advantages and disadvantages?

4. How do students perceived blended PFP?

5. How does blended PFP effect students' perceptions of the teaching profession?

6. How does blended PFP contribute to students' self confidence in terms of the teaching profession?

\section{Method}

In order to understand students' learning experience in blended PFP, this study employed a qualitative case study approach (Bogdan \& Biklen, 1992). The case method allows the researchers to gain comprehensive and in-depth information and understand the selected subjects (Patton, 2002; Yildirim \& Simsek, 2008). In this study, the researcher focused on the students' attendance, self confidence, and perceptions regarding both PFP and the teaching profession. Through the study both online and face-to-face parts of the PFP were considered. 


\subsection{Settings /Context}

Education faculties at universities accredited by the Higher Education Council are the sole teacher training institutions in Turkey. These institutions provide teacher candidates with both content and pedagogic knowledge during 4 or 5 years-training in different subjects. However in the past 30 years, HEC has started Pedagogic Formation Programs to meet the growing need for teachers in schools. PFPs aim to give accelerated pedagogic training to graduated Faculty of Arts and Sciences students who are experts in a different subject. Until 2014, these programs were conducted exclusively through face-to-face education. However, after this year, HEC has allowed educational faculties to give these training courses in a blended format. Several institutions throughout the country have started blended Pedagogic Formation Programs. This study was conducted in one of these institutions and with the first teacher candidates who were taking pedagogic formation education in a blended format.

\subsection{Samples}

The participants of this study consist of 154 newly graduated Faculty of Arts and Sciences students who were attending the blended pedagogical formation program. In total, 1240 graduated Faculty of Arts and Sciences students enrolled in the program with the Distance Education Center. These students were responsible for7 fully online and 3 face-to-face courses that were supported with a content management system. These courses are summarized in Table 1 (HEC, 2014). At the end of the PFP, 154 students out of the total 1240 students voluntarily attended the study. Demographics of the participants are summarized in Table 2.

Table 1. Courses in PFP

\begin{tabular}{|c|c|c|}
\hline \multicolumn{2}{|c|}{ Course Name } & Credit \\
\hline \multicolumn{2}{|c|}{ Fully Online Courses } & 14 \\
\hline \multicolumn{2}{|c|}{ Introduction to Education Sciences } & 2 \\
\hline \multicolumn{2}{|c|}{ Teaching Methods and Principles } & 2 \\
\hline \multicolumn{2}{|c|}{ Assessment and evaluation in education } & 2 \\
\hline \multicolumn{2}{|c|}{ Educational psychology } & 2 \\
\hline \multicolumn{2}{|c|}{ Classroom Management } & 2 \\
\hline \multicolumn{2}{|c|}{ Elective course I } & 2 \\
\hline \multicolumn{2}{|c|}{ Elective course II } & 2 \\
\hline \multicolumn{2}{|c|}{ Face-to-Face Courses } & 11 \\
\hline \multicolumn{2}{|c|}{ Special Teaching Methods } & 3 \\
\hline \multicolumn{2}{|c|}{ Instructional Technology and Material Development } & 3 \\
\hline \multicolumn{2}{|c|}{ School Experience } & 5 \\
\hline \multicolumn{2}{|l|}{ Total } & 25 \\
\hline \multicolumn{3}{|c|}{ 2. Demographics of the participants } \\
\hline Gender & $\begin{array}{l}\text { Department of Department of Mathematics } \\
\text { Literature }\end{array}$ & Total \\
\hline Female & 70 & 96 \\
\hline Male & 34 & 58 \\
\hline Total & 104 & 154 \\
\hline
\end{tabular}

\subsection{Data Collection}

Data was gathered through a questionnaire and focus group interviews. The questionnaire consisted of 3 demographic questions and 7 open-ended questions. 154 students answered the questionnaire voluntarily. Focus group interviews were conducted with 2 groups, one of which consisted of 5 students graduated from the Departments of Literature while the other consisted of 5 students graduated from the Department of Mathematics. For both groups, semi-structured questions were used and interviews were recorded via sound recorder. 


\subsection{Data Analysis}

The qualitative data were analyzed by using content analysis techniques (Miles \& Huberman, 1994). Patton (2002) stated that there is no formula that transforms data into findings, but in Social sciences there are many different approaches for qualitative data analysis. In the present study, the analysis was organized according to the four stages defined by Yildirim and Simsek (2008). These steps were:

(1) Data coding,

(2) Developing themes,

(3) Organizing codes and themes,

(4) Defining and describing the findings and interpretation (p. 228).

Coding was the first stage of the analysis which is defined by Strauss and Corbin (1998, p.3) as "the analytic process through which data are fractured, conceptualized, and integrated to form theory." In this stage, the interview records are transcribed. Answers to the open ended questions were coded using Nvivo8 qualitative data analysis software. Color coding technique was used to developing themes. According to Marshall and Rossman (2006), themes should be internally consisted but also distinct from each other. It was important to develop appropriate themes from related codes. During this process themes were verified and confirmed by two independent researchers. Inter-coder reliability was calculated as 86 percent. Finally, the themes and codes were organized in order to describe the findings.

\subsection{Trustworthiness}

In order to ensure the trustworthiness of the findings, the credibility of the study was addressed as discussed by Lincoln and Guba (1985). Two important techniques were used to enhance the credibility of the study: prolonged engagement and triangulation. Prolonged engagement serves to "built trust and develop a rapport" with the participants (Erlandson, Harris, Skipper, \& Allen, 1993, p.134). Because the researcher is an instructor in the PF program during the semester, he is involved in the classes and has the chance to have a closer relationship with the participants.

The other technique used in this study to establish credibility is triangulation of qualitative data sources. Data were gathered using two common techniques: a questionnaire and a focus group interview. This helped to ensure the credibility of the findings.

\section{Results}

3.1 Which Factors Shape Students' Attendance in Both Face-to-face and Online Education in Blended PFP?

Analysis of the focus group interviews and the responses of participants to open-ended questions revealed that students prefer to attend online and face-to-face education regularly for several reasons. Resulting categories were listed in Table 3. There were five affective factors regarding student's attendance in online courses and eight affective factors for student's attendance in face-to-face education.

Many students stated that they live in city districts or different cities. Therefore, online education was more suitable for them and significantly affected their progression. They also indicated that they encountered some transportation and accommodation problems to attend face-to-face courses but did not face these problems when taking online courses. In this regard, one of them stated;

"Face to face lesson is a necessary part of education but transportation creates financial difficulties and listening to lessons after the journey reduces the efficiency of the courses. Whenever I make a trip I become sick. Also, it affects my sleeping. I cannot sleep when I am in a different bed. If I have a chance to select a preferred type of education, I would choose distance education for teacher education courses."

Another factor shape in students' attendance at blended PFP was learning environment. Roughly twenty students mentioned that online learning was more comfortable and peaceful than classroom environments, and that they prefer to attend classes in the comfort of their home.

"As you know it is summer and the weather is too hot. In this case, a class of 100 people is not a good thing. For that reason I think distance education thing is a good fit me. I followed lessons very easily with my computer and the efficiency of these lessons is unquestionable. We had face-to-face material design lesson. In face-to-face lessons, the teachers are quality but the hot weather and smell of sweat is problematic." 
Students also noted that online classes were recorded and they can watch the lesson whenever they want. Also, they did not have to be in a specific place to attend classes. For example another student stated "My desire to take distance learning classes was higher than my desire to take face-to-face classes. Watching lessons in distance education is easier than face to face lessons."

It was also found that some students were holding a job while taking PFP. Therefore, they tend to progress online classes more regularly. In this regard, one of them stated;

"My desire wish to participate in face-to-face training was low because I am working and I have to earn money. I was very interested in participating in distance learning because education conducted on the internet makes it easy to participate in lessons even at work."

Another subtheme that emerged under the students' reasons for attending online classes was that the classes were the first online experience for them. Two students said that it was the first time they took online courses and that it positively affected their desire to attend courses.

On the other hand, the analysis showed that participants prefer to attend face-to-face education for several reasons. Mostly students stated that they tend to prefer face-to-face courses because they think face-to-face courses are effective and efficient. All 10 interview participants emphasized the same point. For example one student stated "I wanted to attend face-to-face courses because I don't forget everything teachers told in face-to-face lessons."

Several students also indicated that face-to-face learning was more authentic and real than the online environment. Because of that they were more ambitious to attend face-to-face courses.

Another subtheme that emerged under the students' reasons for attending face-to-face classes was having good communication with the instructors and the other students. One student indicated;

"My desire to participate in face-to-face lessons was higher than others. Because of that, we have a classroom ambiance and ability to communicate with the teacher in person. I think lessons which are conducted face-to-face are better than others because one has opportunity to ask questions to teachers and reducing distractibility and that help your understanding capacity."

Students also mentioned that connection problems happened while taking online courses. Therefore, several students failed to progress in online classes. They attended face-to-face classes more regularly. In addition, some students asserted that face-to-face education motivated them to attend the classes. In this regard five interview participants compared face-to-face education with online education and they indicated that face-to-face education was more attractive than online education.

Moreover, a few students cited gaining experience and being active in classes, as well as retaining subjects they learn in class better as reasons for attending face-to-face class.

Table 3. Students' attendance reasons of online and face-to-face classes

\begin{tabular}{ll}
\hline Themes/Categories & Frequency $(\mathrm{n}=152)$ \\
\hline Students' attendance reasons of online classes & $64(49 \%)$ \\
Distance & $28(21 \%)$ \\
Learning Environment & $20(15 \%)$ \\
Accessibility & $8(6 \%)$ \\
Having job & $6(5 \%)$ \\
First online experience & $2(2 \%)$ \\
Students' attendance reasons of face-to-face classes & $66(51 \%)$ \\
Effectiveness & $17(13 \%)$ \\
Authenticity & $11(8 \%)$ \\
Good communication & $10(8 \%)$ \\
Connection problems in online courses & $10(8 \%)$ \\
Motivation & $9(7 \%)$ \\
Experience & $4(3 \%)$ \\
Retention & $3(2 \%)$ \\
Active Learning & $2(2 \%)$ \\
\hline
\end{tabular}




\subsection{What are the Views of the Students on the Effect of Face-to-face and Online Education on Their Professional Development?}

Students were asked which approach, face-to-face or online education, better prepared them for the teaching profession and why. The data analysis indicated that most of the survey participants and all 10 interview participants felt that despite some disadvantages, face-to-face education better prepared them for the teaching profession. Only twelve students indicated that online education better prepared them, while sixteen students expressed that there was no difference between face-to-face and online approach. In Table 4, the participants' reasons for selecting face-to-face education were presented.

Table 4. The Reasons for Selecting Face-to-face Education

\begin{tabular}{ll}
\hline Themes/Categories & Frequency (n=152) \\
\hline Applied & $29(35 \%)$ \\
Authentic & $21(25 \%)$ \\
Communication & $12(14 \%)$ \\
Motivation & $9(11 \%)$ \\
Permanence & $8(10 \%)$ \\
Technical/Connection problems & $4(5 \%)$ \\
Total & $83(100 \%)$ \\
\hline
\end{tabular}

About half of the students stated that face-to-face education was applied and authentic, and therefore this method prepared them adequately for the teaching profession. One of them stated;

"Face-to-face trainings help prepare me for my job better than the other methods. Because being in the classroom ambiance, interacting with the class and concentrating on the subject makes the experience more effective. This way is more efficient and successful for a preparing phase."

The other three important subthemes that emerged in data analysis were communication, motivation and permanence. Students indicated that they had effective communication with friends and teachers in face-to-face courses but they could not establish effective communication in the online environment. Several students also stated that they were more motivated in face-to-face courses which in turn affected their professional development. Moreover, several students emphasized that what they learned in face-to-face courses was more permanent than in online courses.

Lastly a few students indicated that technical problems, mostly connection problems, negatively affected their professional development in the online environment. For example one student stated;

"I think face-to-face trainings achieve more for students. We can more easily retain what we learned in face-to-face trainings, and there can be some technical problems in distance education. I didn't have any problems in face-to-face trainings."

On the other hand, as stated above, twelve students argued that online education was better than face-to-face education regarding preparation for a teaching career. The reasons that students mentioned were access to video records of the online classes and access to synchronous classes from anywhere with an Internet connection.

\subsection{How do Students Perceive Online Education in Blended PFP? What are the Advantages and Limitations?}

Students' opinions centered around two main subthemes of the advantages (52\%) and limitations (48\%) of online education in PFP. In Table 5, advantages indicated by participants were presented. Accessibility was the most mentioned advantage of the online education. Three main points emerged under "accessibility": time, environment and repetition. Students indicated that they can study online any time and attend classes at home or job wherever they were. Also they watch recorded classes over again. One student said;

"There are some advantages in distance education, for example I can Access lecture videos whenever I want and these videos give me the opportunity to study and watch videos again. Especially during the exam period, that is a big advantage for me."

Environment emerged as another subtheme. Students clearly stated that being able to set the physical conditions of the environment while taking online courses was an important advantage of online education. For example one student stated "Because I follow online lessons at my home, I can create the learning environment. For that reason my learning facilities become independent from environment and more efficient." 
Lastly students indicated that taking online courses was time efficient because of two reasons. Firstly, students did not spent time traveling to the classroom. Second, some students indicated that they could multi-task while taking online courses. For example one student said, "We can do research on internet while listening to the teacher online. It is an advantage for me."

On the other hand, four subthemes emerged as limitations of online PFP (see Table 5). Students indicated that they had attention and motivation problems in the online classes. All 10 interview participants also highlight that it was hard to concentrate on the topic of the classes in an online environment. One of the students stated;

"I have high motivation in face-to-face lessons but not in distance education. There is nothing to hold our attention in distance learning. There can be some distractions in online lessons, like guests who come in our home for visit. For several reasons, distractions may occur at the same time as lessons."

Students also reported that they had technical problems, mostly having to do with the Internet connection. Sometimes they could not establish a connection to the online learning environment or their connection was broken repeatedly. Another subtheme that emerged under the limitation of online PFP was ineffective communication. Students asserted that good communication was not established with the instructor in the online environment. It was also emphasized that they could not ask their questions to the instructor.

Lastly, several students indicated that what they learned in the online environment could not be retained as well as in face-to-face environment. They put face-to-face education before online education regarding retainment (?).

Table 5. Advantages and Limitations of Online education in PFP

\begin{tabular}{ll}
\hline Themes/Categories & Frequency $(\mathrm{n}=152)$ \\
\hline Advantages & $85(52 \%)$ \\
Accessibility & $42(26 \%)$ \\
Environment & $26(16 \%)$ \\
Saving of Time & $17(10 \%)$ \\
Limitations & $80(48 \%)$ \\
Motivation & $29(17 \%)$ \\
Technical / Connection Problems & $26(16 \%)$ \\
Communication & $17(52 \%)$ \\
Permanence & $8(52 \%)$ \\
\hline
\end{tabular}

3.4 How They Perceived Contribution of the Blended PFP?

Students were asked students what they think about the blended PFP. Generally, the blended PFP was perceived positively by the students. However, it was perceived differently by the some students. In Table 6, perceptions of participants were presented under the seven subthemes.

About half of the students believed that the blended PFP prepared them adequately for the teaching profession. They emphasized that this program allows them to learn how to prepare learning materials, which methods and technologies they should use in teaching, which assessment method they should use, how to establish good communication and how to hold the students attention. For example, one student said;

"We got answers to our questions, such as "How should we teach?", "How should we approach students?" and "How should we explain the subjects so that the students achieve objectives most efficiently?" In this respect, I think we were prepared well."

In addition to this, several students stated that blended PFP provide them with a better understanding of teaching profession. Also some other students indicated that this program was just an introduction to the teaching profession. Similarly, some students indicated that they need more practice. They had some practice opportunities during the blended PFP but they thought that more practice was needed. One of them asserted, "We are just creating a background now. We need more practice to become a fully prepared teacher."

On the other hand, results showed that some students have found this program to be inadequate. They think that this program was not efficient enough and did not prepare them to begin teaching. Mostly, they indicate that the teaching profession is an art, not a simple job, and therefore it cannot be learned so easily. Also they indicated that in order to be a teacher, someone should feel emotionally ready and must do more practice. 
Some other students who thought about the program positively indicated that blended PFP was efficient but not enough to be a good teacher. Individual efforts and motivation for the teaching profession were crucial. They stated that this training was important to be a good teacher, but in addition to this, individual efforts were necessary.

Lastly, confidence and technology emerged as subthemes. A few students indicated that blended PFP increased their confidence about the teaching profession. A few students also stated that this program improved their awareness of new technologies.

Table 6. Perceptions of Participants

\begin{tabular}{ll}
\hline Themes/Categories & Frequency $(\mathrm{n}=152)$ \\
\hline Prepare for Teaching Profession & $58(41 \%)$ \\
Insufficient & $25(18 \%)$ \\
Practicing & $21(15 \%)$ \\
Individual Effort and Motivation & $12(9 \%)$ \\
Understanding Teaching Profession & $9(6 \%)$ \\
Introduction to Teaching Profession & $9(6 \%)$ \\
Confidence & $4(3 \%)$ \\
Technology & $3(2 \%)$ \\
Total & $141(100 \%)$ \\
\hline
\end{tabular}

\subsection{How Blended PFP Affect Their Perceptions toward Teaching Profession}

Most of the students, including all interview participants, indicated that PFP provide effective preparation for the teaching profession. On the other hand, only 10 students expressed that PFP did not affect their preparedness much, and 3 students said that PFP negatively affected them in terms of motivation for teaching profession. In Table 7, students' positive perceptions were presented under subthemes.

Many students believed that PFP motivated them and made them feel ready to start teaching. PFP also improved their teaching abilities, such as raising their own students' motivation in class, using educational materials, methods and facilitators, and communicating with students. One of them stated;

"I learned many things, especially about the psychology of students. I was happy to learning the settings. We also learned how to use computers for educational purposes."

Moreover, analysis indicated that PFP allows students to gain a broad perspective regarding the responsibilities of teachers, the importance of communication, and psychological characteristics of students. Some other students stated that PFP provided a teacher perspective that helped them to have a pedagogical view. One student stated "We saw behind the scenes of the classroom, the unseen side of being a teacher. I see now a teacher must handle many things at the same time. I learned what I should do as a teacher." Lastly, students expressed that PFP increased their respect toward the teaching profession.

Table 7. Students' Positive Perceptions toward PFP Regarding Teaching Profession

\begin{tabular}{ll}
\hline Themes/Categories & Frequency $(\mathrm{n}=152)$ \\
\hline Motivate to teaching profession & $23(25 \%)$ \\
Improve teaching abilities & $16(17 \%)$ \\
Broad perspective & $14(16 \%)$ \\
Gaining teacher perspective & $11(13 \%)$ \\
Respect to teacher profession & $9(10 \%)$ \\
Total & $73(100 \%)$ \\
\hline
\end{tabular}

3.6 How Blended PFP Contributes to Students' Self Confidence in Terms of the Teaching Profession

The analysis of the focus group interviews and the responses of participants to open-ended questions revealed that most of the students believed that blended PFP affected their self-confidence positively (see Table 8). While 5 students indicated that they need more practice to build self confidence, only 8 students, including one interview participant, stated that their self-confidence was not affected from PFP. However, when the 8 students' responses 
were examined, it was seen that 4 students said that they already felt fully confident before PFP. One teacher candidate cited the contribution of PFP to his self confidence as follows;

"This training program affected my self-confidence positively. It reduced my nervousness or anxiety, increased my self-confidence and gave me opportunity to understand how to provide and interpreting formation. It showed me that teaching is not hard as it seems."

Table 8. Contribution of PFP to Students' Self Confidence

\begin{tabular}{ll}
\hline Themes/Categories & Frequency $(\mathrm{n}=152)$ \\
\hline Positive effect & $147(92 \%)$ \\
No effect & $8(5 \%)$ \\
Need more practice & $5(3 \%)$ \\
Total & $160(100 \%)$
\end{tabular}

Moreover, the analysis showed that students feel that their self confidence increased because of five factors. Resulting categories were listed in Table 9. About half of the students emphasized that this program provides them with important knowledge and skills including how to prepare learning materials, which methods and technologies they should use, which assessment method can be use, how good communication is established and how to keep students' attention. For example one student said;

"I think this study helped me to gain some self-confidence. I learned how to deal with students and present the subjects in the classroom in the correct way."

Students also expressed that the experiences they had in face-to-face classes encouraged them in the teaching profession. For example one student said;

"Interactions in $\mathrm{f} 2 \mathrm{f}$ classes and the knowledge we gained from teachers increased my self-confidence in the teaching profession."

Moreover, students believed that blended PFP raised their awareness and helped them to get used to the teaching profession. Lastly, participants indicated that this program increased their self-confidence by motivating them as teachers. They also emphasized that blended PFP showed that this job was appropriate for them.

Table 9. Contribution factors

\begin{tabular}{ll}
\hline Themes/Categories & Frequency $(\mathrm{n}=152)$ \\
\hline Knowledge and skills & $30(45 \%)$ \\
Experience in FCT classes & $14(21 \%)$ \\
Awareness and adaptation & $12(18 \%)$ \\
Motivate & $8(12 \%)$ \\
Appropriate for me & $3(4 \%)$ \\
Total & $67(100 \%)$ \\
\hline
\end{tabular}

\section{Discussion and Conclusion}

The goal of this study was to investigate the learning experience of students studying pedagogic formation in blended design with regard to attendance, self confidence, and attitudes toward both PFP and the teaching profession. Data analysis revealed that teacher candidates prefer to regularly attend online and face-to-face courses in blended design for several reasons. Attendance of online classes was mainly dependent on students' available time and the distance between home and school. Also they prefer to attend classes in the comfort of their home. This finding corroborates previous studies that students prefer online education because they spend less money on travel and less time sitting in the classroom (e.g., Beard \& Harper, 2002; Carrell \& Menzel, 2001; Chamberlin, 2001; Guidera, 2004). On the other hand, participants preferred to attend the face-to-face section regularly because they think face-to-face classes are more effective, authentic and allow for better communication. Traditional environments build a sense of belonging by utilizing teamwork, discussion groups and group assignments (Aviv, 2000). In addition, teacher candidates argued that face-to-face education certainly prepares candidates well for the teaching profession while the gains from online education are less certain. About half of the students stated that face-to-face education was applied and authentic therefore this method prepared them adequately for the teaching profession. They also believe that the f2f environment was more motivating than online environment. In their study, Collopy and Arnold (2009) stated that 
teacher candidates may feel more alone and isolated while taking courses or working in the online section of the blended design.

Results revealed that teacher candidates believed that the most significant advantage of the online section of blended learning was to provide to easy access to the lessons and other resources. On the other hand, motivation problems in online classes were highlighted as a major limitation. All interview participants stated that it was hard to be concentrated on the topic in the online environment.

Teacher candidates generally held positive perceptions of the blended PF program. This result was not surprising, many studies conducted in blended environments have found similar results (e.g., Li, 2015; Gunter, 2001; Sanders \& Morrison-Shetlar, 2001). About half of the participants believed that the blended PFP prepared them adequately for the teaching profession. Moreover, analysis indicated that PFP allowed students to gain a broad perspective regarding responsibilities of teachers, importance of communication, and various psychological characteristics of students. However, some students believe that they need more practice and experience and still others have found this program is inadequate. This result differ from the findings of the study of Jackson and Helms (2008) which indicated that hybrid classes do not minimize weaknesses online format and continued to hold the similar weaknesses. However, the result of this study showed that inherent problems of online education continue to take place but a well design blended education can minimize these weaknesses. For example, teacher candidates who do not meet their communication needs in the online section reported that they had better communication in the f2f section; as a result their overall feelings toward the blended program were positive. Similarly, in a recent study, researchers conducted a path analysis and concluded that students' feelings, especially motivation, were directly affected by the perceived quality of the f2 $\mathrm{f}$ part of the blended design (Kassab, Al-Shafei, Salem, \& Otoom, 2015).

This study also indicated that almost all of the students believed that blended PFP affected their self-confidence positively. Only 8 students stated that their self-confidence was not affected from PFP. However, when the 8 students' responses are examined, it is clear that 4 students already felt full self confidence before PFP. Overall this result corresponded with Collopy and Arnold's (2009, p.97) following observations;

"blended classes reported significantly greater feelings of competence and comfort ..."

Teacher educators and instructional technologists' cooperative endeavors were to use the technology in teacher education effectively. The aim was to train more qualified and more skilled teachers in an efficient and appropriate way. Overall this study showed that blended education was highly promising regarding teacher education. However blended programs have to maintain a sensible balance between online and $\mathrm{f} 2 \mathrm{f}$ sections to allow teacher candidates sufficient practice facilities. Otherwise, there is a continued risk that blended design may not eliminate the disadvantages of online education. Further studies which utilize both qualitative and quantitative methodologies should be helpful to gain insight about how blended learning use effectively in teacher education programs.

\section{References}

Aragon, S. R., Johnson, S. D., \& Shaik, N. (2002). The influence of learning style preferences on student success in online versus face-to-face environments. The American Journal of Distance Education, 16(4), $227-243$. https:/doi.org/10.1207/S15389286AJDE1604_3

Aviv, R. (2000). Educational performance of ALN via content analysis. Journal of Asynchronous Learning, 4(2), 53-72.

Beard, L. A., \& Harper, C. (2002). Student Perceptions of Online Versus on Campus Instruction. Education, 122(4), 658-663.

Bogdan, R., \& Biklen, S. K. (1992). Qualitative Research for Education. Boston: Allyn and Bacon.

Carlson, S. (2004, November 26). Online education survey find sun expectedly high enrollment growth. Chronicle of Higher Education, 51, p. 30.

Carrell, L. J., \& Menzel, K. E. (2001). Variations in learning, motivation, and perceived immediacy between live and distance education classrooms. Communication Education, 50(3), $230-240$. https:/doi.org/10.1080/03634520109379250

Chak, S. C., \& Fung, H. (2015). Exploring the Effectiveness of Blended Learning in Cost and Management Accounting: An Empirical Study. In New Media, Knowledge Practices and Multiliteracies (pp. 189-203). Springer Singapore. https:/doi.org/10.1007/978-981-287-209-8_18

Collopy, R., \& Arnold, J. M. (2009). To Blend or Not to Blend: Online and Blended Learning Environments in Undergraduate Teacher Education. Issues in Teacher Education, 18(2), 85-101. 
Delialioglu, O., \& Yildirim, Z. (2008). Design and development of a technology enhanced hybrid instruction based on MOLTA model: Its effectiveness in comparison to traditional instruction. Computers \& Education, 51(1), 474-483. https:/doi.org/10.1016/j.compedu.2007.06.006

Erlandson, D. A., Harris, E. L., Skipper, B. L., \& Allen, S. D. (1993). Doing Naturalistic Inquiry: A Guide to Methods. Beverly Hills, CA: Sage.

Garrison, D. R., \& Kamuka, H. (2004). Blended learning: Uncovering Its Transformative Potential in Higher Education. The Internet and Higher Education, 7(2), 95-105. https:/doi.org/10.1016/j.iheduc.2004.02.001

Guidera, S. G. (2004). Perception of the Effectiveness of Online Instruction in Terms of the Seven Principles of Effective Undergraduate Education. Journal of Educational Technology, 32(2/3), 139.

Gunter, G. A. (2001). Making a Difference: Using Emerging Technologies and Teaching Strategies to Restructure an Undergraduate Technology Course for Pre-Service Teachers. Educational Media International, 38(1), 13-20. https:/doi.org/10.1080/09523980010021190

HEC (2014). Pedagojik Formasyon Eğitimi Sertifika Programına İlişkin Usul ve Esaslar. Retrieved from http://www.yok.gov.tr/web/guest/icerik/-/journal_content/56_INSTANCE_rEHF8BIsfYRx/10279/7052802

Jackson, M. J., \& Helms, M. M. (2008). Student Perceptions of Hybrid Courses: Measuring and Interpreting Quality. Journal of Education for Business, 84(1), 7-12. https:/doi.org/10.3200/JOEB.84.1.7-12

Kassab, S. E., Al-Shafei, A. I., Salem, A. H., \& Otoom, S. (2015). Relationships between the quality of blended learning experience, self-regulated learning, and academic achievement of medical students: a path analysis. Advances in Medical Education and Practice, 6, 27-34. https:/doi.org/10.2147/AMEP.S75830

Klesius, J. P., Homan, S., and Thompson, T. (1997). Distance education compared to traditional education: The students' view. International Journal of Instructional Media, 24, 207-222.

Ko, S., \& Rossen, S. (2008). Teaching online: A practical guide. New York: Routledge.

Krippendorff, K. (2004). Content Analysis: An Introduction to Its Methodology (2nd ed.). Thousand Oaks, CA: Sage.

Lilja, D. J. (2001). Comparing Instructional Delivery Methods for Teaching Computer Systems Performance Analysis. IEEE Transactions on Education, 44(1), 35-40. https:/doi.org/10.1109/13.912708

Li, Y. (2015). Blended Learning in English for Tourism: A Case Study. In Exploring Learning \& Teaching in Higher Education (pp. 331-345). Springer Berlin Heidelberg. https:/doi.org/10.1007/978-3-642-55352-3_15

Lincoln, Y. S., \& Guba, E. A. (1985). Naturalistic inquiry. Beverly Hills, CA: Sage.

Marshall, C., Rossman, G. B. (2006). Designing Qualitative Research (4th ed.).Thousand Oaks: Sage.

Martyn, M. (2003). The hybrid online model: Good practice. Educause Quarterly, 26(1), 18-23.

Miles, M.B., \& Huberman, A. M. (1994). Qualitative Data Analysis: An Expanded Sourcebook (2nd ed.). California: Sage.

Patton, M. Q. (2002). Qualitative Research and Evaluation Methods (3th ed.). Thousand Oaks, CA: Sage.

Pethokoukis, J. M. (2002). E-learn and earn: As dot coms mostly fade, online universities are proving that there's gold in them than screens. U.S. News and World Report, 132(22), p. 36.

Russell, T. L. (1999). The no significant difference phenomenon: A comparative research annotated bibliography on technology for distance education: As reported in 355 research reports, summaries and papers. North Carolina State University.

Sanders, D. W., \& Morrison-Shetlar, A. I. (2001). Student Attitudes toward Web-Enhanced Instruction in an Introductory Biology Course. Journal of Research on computing in Education, 33(3), 251-262. https:/doi.org/10.1080/08886504.2001.10782313

Strauss, A., \& Corbin, J. (1998). Basics of qualitative research: Techniques and Procedures for Developing Grounded Theory. Thousand Oaks, CA: Sage Publications, Inc.

Tuckman, B. W. (2002). Evaluating ADAPT: A hybrid instructional model combining web-based and classroom concepts. Computers \& Education, 39, 261-269. https:/doi.org/10.1016/S0360-1315(02)00045-3

Yıldırım, A. \& Şimşek, H. (2008). Sosyal Bilimlerde Nitel Araştırma Yöntemleri (6. baskı). Ankara: Seçkin Yayıncılık.

Zurita, G., Hasbun, B., Baloian, N., \& Jerez, O. (2015). A Blended Learning Environment for Enhancing Meaningful Learning using 21st Century Skills. In Emerging Issues in Smart Learning (pp. 1-8). Springer Berlin Heidelberg. https:/doi.org/10.1007/978-3-662-44188-6_1 